\title{
A NOVEL METHOD OF MPPT ALGORITHM USING CSO ASSISTED P\&O FOR SOLAR SYSTEMS
}

\author{
R. Jenin Prabhu \\ Assistant Professor, \\ Vel Tech, Chennai, \\ India
}

\author{
J. Muruganantham \\ UG Student \\ Vel Tech, \\ Chennai, India,
}

\author{
V. Pavithran \\ UG Student \\ Vel Tech, \\ Chennai, India
}

\author{
A. Sanjay Kumar \\ UG Student \\ Vel Tech, \\ Chennai, India
}

\begin{abstract}
The chicken swarm optimization algorithm is a new biology optimization algorithm, but its highdimensional operation generally causes deviation and the generation time of optimizing is a little long. An increased chicken swarm optimization algorithm is proposed. In the increased algorithm, preliminary positions are arranged according to chaotic sequence; therefore, the uniformity and ergodicity of population are enhanced. Adaptive inertia weight is delivered to replace the rule of hens; thus, the velocity of global search and the potential of local search are enhanced. The following coefficient of chicks is changed into random quantity, so the danger of falling into local extremum is avoided. These enhancements beautify the search capability in the early stage and the music ability in the late stage of the algorithm. The multiplied algorithm is applied in the most electricity point monitoring manipulate of the photovoltaic gadget and is compared with other algorithms.
\end{abstract}

Keywords - chicken swarm optimization CSO), maximum power point (MPP), perturb and observe ( $\mathrm{P \& O}$ ), partial shading conditions (PSCs).

\section{INTRODUCTION}

In a PV electricity gadget, partial shading is a nun keep away from in a position complication that notably reduces the efficiency of the normal machine resulting in multiple peaks with numerous local and one international peak (GP). Thus, finding out this height leads to a extraordinary challenge for designing an appropriate MPP tracker (Subudhi and Pradhan, 2013; Brito et al., 2013; Elgendy et al., 2015; Elgendy et al., 2013; Elgendy et al., 2016; Ishaque et al., 2012), (Chen et al., 2014) for a PV system. A method to determine the incidence of partial shading accompanied by means of a ramp exchange in obligation cycle with non-stop sampling to determine the international top is discussed in (Ghasemi et al., 2016; Tey and Mekhilef, 2014; Sundareswaran et al., 2014) achieving quicker convergence towards the Gp beneath partial shading. A new sensor-less Hybrid MPPT is proposed in (Sher et al.,
2015) which exhibits low strength oscillation around the MPP. Relationship between the load line and I-V curve with trigonometric rule has been proposed too btaina quick MPPT tracking response. A nent colony based MPPT has been proposed in (Sundareswaran et al., 2016), which is found to track the GP with minimal time and low computational overhead. Currently, soft computing techniques such as particle swarm optimization (PSO) (Ishaque et al., 2012) and many other evolutionary alga- rhythms are used for developing MPPT techniques to track the GP under PSCs. Currently, soft computing strategies such as particle swarm optimization (PSO) (Ishaque et al., 2012) and many other evolutionary alga- rhythms are used for creating MPPT strategies to track the GP under PSCs.

In (Mohanty et al., 2016), authors have enveloped a CSOMPPT technique which is able to track the GP under PSCs. After have- in pursued the certain convergence analysis i.e. the time taken to attain the GP by means of the CSO and P\&O MPPTs, in this modern paper, we have attempted to combine these two MPPTs. The above combination is aimed at achieving faster tracking of the $\mathrm{Gp}$ via the proposed hybrid CSO-P\&OMPPT technique to hand lerapidlyvaryinginsolation patterns. In the proposed mixture of CSO-MPPT and P\&OMPPT, the former approach is used in off-line to carry the running factor of the PV array close to the genuine MPP and then the later method is used in on-line to track the MPP with higher accuracy. Such fusion of off-line and online MPPT strategies makes quickly tracking and guar-antees world convergence for handling rapidly varying photo voltaic insolationpatterns.

The goal of this paper is to appoint a dynamic global MPPT technique through combining a CSO optimizer with P\&O MPPT which can cope with PSCs with a motivation of its implementation in a sensible PV system.

\section{PARTIAL CONDITION}

When one(or many) of the module in a solar panel comes under the impact of shading(which can be due to trees, neighboring buildings, clouds and many extra circumstances 
can be there), its voltage drops, so, it works as a load instead of working as a generator (Subudhi and Pradhan, 2013). A skip diode is connected to make sure that specific shaded module doesn't get damaged. Voltage mismatch can manifest in parallel related modules. So, a blockading diode is related for offering safety below such conditions.

Under Partial shading (when some part of module is under shading), bypass diode starts conducting. So, in P-V curve we do not get a unique maximum power point (MPP) but receive several local peaks and one MPP. Bypass diode can be uninstalled from the system to simplify the complications of so many peaks, but as a result power is reduced which significantly increase the cost of solar power generation. So, a bypass diode is not removed.

\section{A. Perturb and Observe $(P \& O) M P P T$}

P\&OMPPT tracks the MPP by perturbing the operating poi and then watching the change in power before and afte $r$ perturbations. This $\mathrm{P} \& \mathrm{O}$ is regarded as the reference for any new MPPT to compare, as it is one of the best MPPT spopularly used. The P\& Obased MPPT algorithm firstcalculates the power(P) of the PV array by means of measuring its voltage and current. Then, it gives a perturbation in the duty cycle based on the version of power through following the rule (Brito et al., 2013):

$$
\begin{aligned}
& \text { dew }=\text { doled }+\varphi(\text { if } \mathrm{P}>\text { Plod }) \\
& \text { dew }=\text { doled }-\varphi(\text { if } \mathrm{P}>\text { Plod })
\end{aligned}
$$

here, $\varphi$ denotes perturbed responsibility cycle. If $\varphi$ is large, con- vergence is faster and constant nation oscillation is high and vice versa.

\section{PRSIMUlation CASESTUdies}

Shading stipulations and swiftly altering insolation levels. Fig. 3 shows the structural outlay of a PV system consisting of PV array, dc-c improve converter, MPPT controller and a load. For simulation studies, the parameters of the PV module taken formodelling are as follows:

$$
\begin{aligned}
& \text { Pmax }=200 \mathrm{~W}, \quad \text { Voc }=32.8 \mathrm{~V}, \quad \text { Isc=8.21A, } \\
& \text { Vmp=26.3VandImp=7.61A }
\end{aligned}
$$

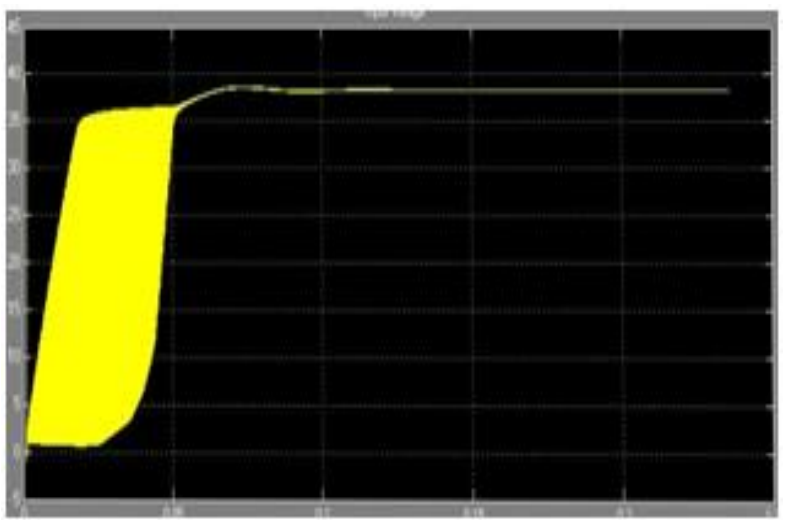

Figure 1 Input voltage



(a)

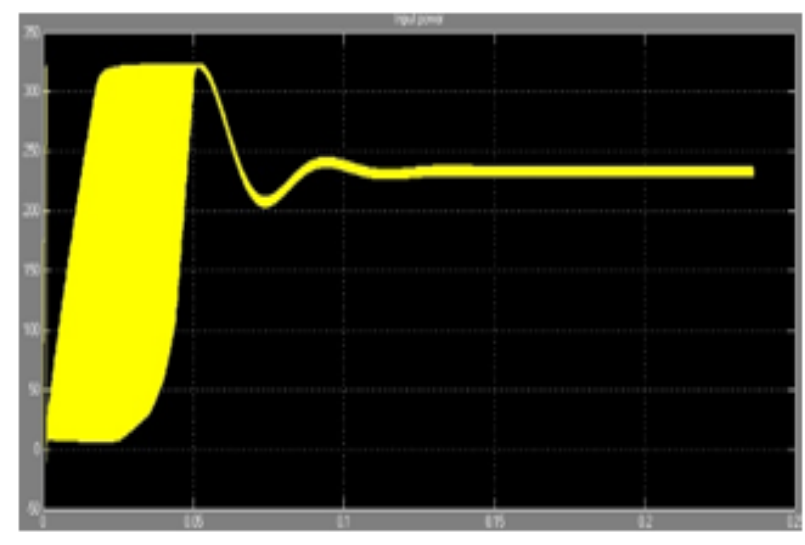

(b)

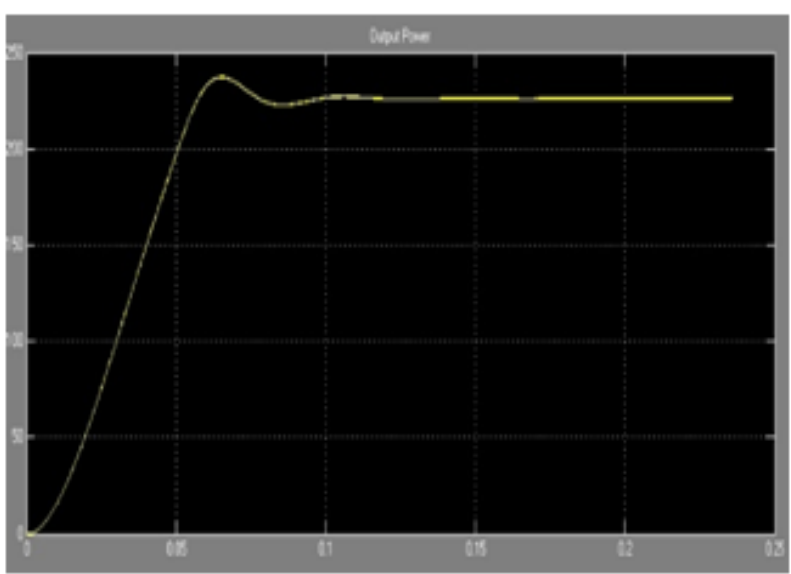

(c)

Figure 2 (a) (b) (c) Output Voltage 


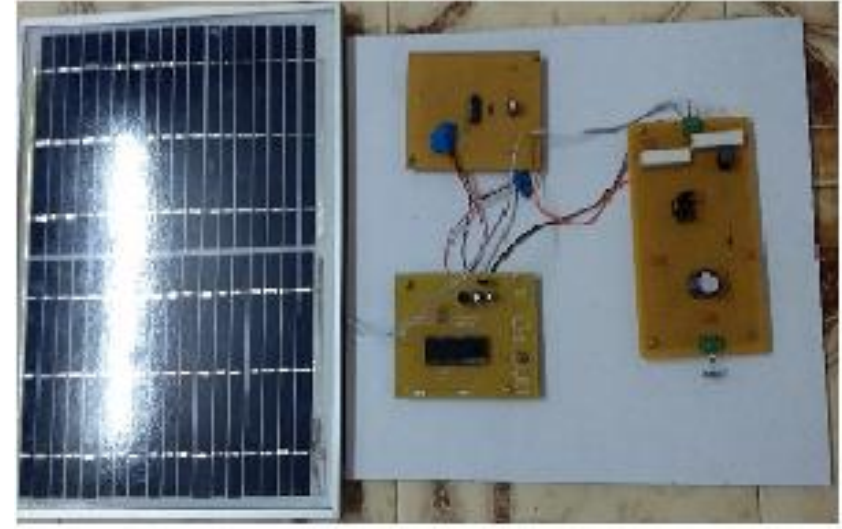

Figure 3 PV system

Input power: From the input power simulation Output power: From your power simulation.

\section{EXPERIMENTAL RESULT}

Each sample used to be modified at $0.1 \mathrm{~s}$ interval each. genuinely indicates that both CSO-PO and CSO- MPPT tune the GP with no oscillation but the CSO-PO hybrid-MPPT reaches the GP at minimal time as in contrast to the CSOMPPT. The PSO-PO MPPT is capable to tune the GP however with oscillations. From the simulation effects introduced above, it is found that the CSO-PO hybrid-MPPT can deal with speedy changing in-solation patterns and it outperforms both PSO-PO and CSO MPPTs in terms of faster convergence to the GP, tracking speed, decreased oscillations, and greater efficiency.

In order to verify the efficacy of the proposed Hybrid MPPT, experiments have been carried out for both $3 \mathrm{~S}$ and 3S2P con-figurations for this experimentation. The experimental set up is shown in Fig. 11. A solar array simulator (SAS), Agilent. (E4360A) is used in this experiment to emulate the PV source power with various situations such as rapidly changing solar insolation. It is a current source with $600 \mathrm{~W}$ dc output source in which it is possible to generate I-V and $\mathrm{P}-\mathrm{V}$ curves of PV arrays under different conditions

This will raise the LEDs driver to either decrease its intensity or increase its light intensity by pulse width modulation. The controller of the public road regulator can also make adjustment to the sensing unit based on the data collected. The street lighting system will directly collects the AC power from the power supply unit with the driver to covert the AC to DC voltage source to drive the LEDs (Liang et al., 2014).

The flow chart in Fig B is the efficient lighting system that lists the criteria for the adjustment of the LEDs street lamp intensity. The microcontroller checks if the light sensor value is above or below 400 lux to determine if the sun has already set. Once the lux level is below 400 lux, the system will start the operation. It now checks if a specific infrared sensor has detected any motion of vehicles or pedestrian. The microcontroller will immediately turn on that street light to operate at $100 \%$ intensity if $\mathrm{SENSOR}=1$, affirming the presence of traffic and loop back otherwise to read from Light sensor. After the system has turned on its street light to $100 \%$, it will now check if the vehicle is still in the vicinity via the neighbouring infrared sensor. If it is affirmed to be positive, then the street lamp will continue to operate at $100 \%$ intensity. If not, it will activate a counter and count for a fixed period of time to reduce back to operating intensity at dimmed level, (at $50 \%$ of its full intensity).

\section{CONCLUSION}

In order to verify the efficacy of the proposed Hybrid MPPT, experiments have been carried out for both $3 \mathrm{~S}$ and 3S2P configurations for this experimentation. The experimental set up is proven in Fig. eleven A solar array simulator (SAS), Agilent. (E4360A) is used in this scan to emulate the PV source electricity with superior performance such as higher tracking speed and faster convergences toward the GP.

\section{REFERENCES}

[1]de Brito,M.,Galotto,M., Sampaio,L.,e Melo ,G. and Canesin,C.(2013)Evaluation of the Main MPPT Techniques for Photovoltaic Applications, IEEE Transactions on Industrial Electronics,60, (3), 1156-1167

[2]Chen,K.,Tian,S., Cheng,Y. and Bai,L.,(2014) An Improved MPPT Controller for Photovoltaic System Under Partial Shading Condition IEEE Transactions on Sustainable Energy, 5, (3), 978-985.

[3]Elgendy,M.,Atkinson,D. and Zahawi,B.(2016) Experimental investigation of the incremental conductance maximum power point tracking algorithm at high perturbation rates IET Renewable Power Generation, 10, (2), 133-139..

[4]Elgendy,M., Zahawi,B. and Atkinson,D.(2013) Assessment of the Incremental Conductance Maximum Power Point Tracking Algorithm IEEE Transactions on Sustainable Energy, 4, (1), 108-117.

[5]Elgendy,M.,Zahawi,B. and Atkinson,D.(2015) Operating Characteristics of the P\&amp;O Algorithm at High Perturbation Frequencies for Standalone PV Systems IEEE Transactions on Energy Conversion, 30, (1),189198.

[6]Ghasemi,M., Foroushani,H. and Parniani, M.(2016) Partial Shading Detection and Smooth Maximum Power Point Tracking of PV Arrays Under PSC IEEE Transactions on Power Electronics, 31, (9), 6281-6292.

[7]Ishaque,K., Salam,Z., Amjad,M. and Mekhilef,S.,(2012) An Improved Particle Swarm Optimization (PSO)-Based MPPT for PV With Reduced Steady-State Oscillation IEEE Transactions on Power Electronics, 27, (8), 36273638 . 
[8]Ishaque,K., Salam, Z., Shamsudin ,A.and Amjad,M.(2012) A direct control based maximum power point tracking method for photovoltaic system under partial shading conditions using particle swarm optimization algorithm Applied Energy, 99, 414-422.

[9] Mohanty,S., Subudhi ,B.and Ray,P.(2016) A New MPPT Design Using Grey Wolf Optimization Technique for Photovoltaic System Under Partial Shading Conditions IEEE Transactions on Sustainable Energy, 7, (1), 181188.

[10]Sher,H., Murtaza,A., Noman,A., Addoweesh,K.,AlHaddad,K. and Chiaberge,M(2015) A New Sensorless Hybrid MPPT Algorithm Based on Fractional ShortCircuit Current Measurement and P\&O MPPT IEEE Transactions on Sustainable Energy, 6, 4, 1426-1434.

[11] Soon,T., and Mekhilef,S.(2015) A Fast-Converging MPPT Technique for Photovoltaic System Under FastVarying Solar Irradiation and Load Resistance IEEE Transactions on Industrial Informatics,. 11, (1), 176-186.

[12]Subudhi,B., and Pradhan,R.(2013) A Comparative Study on Maximum Power Point Tracking Techniques for Photovoltaic Power Systems IEEE Transactions on Sustainable Energy, 4, (1), 89-98.

[13]Sundareswaran,K., Vignesh kumar,V. and Palani,S.,(2015) Application of a combined particle swarm optimization and perturb and observe method for MPPT in PV systems under partial shading conditions Renewable Energy, 75, 308-317.

[14]Sundareswaran,K., Vigneshkumar,V., Sankar,P., Simon,,S., Srinivasa Rao Nayak,P. and Palani,S.,(2016) Development of an Improved P\&O Algorithm Assisted Through a Colony of Foraging Ants for MPPT in PV System IEEE Transactions on Industrial Informatics, 12, (1), 187-2000.

[15]Kok Soon Tey and Mekhilef,S.,(2014) Modified Incremental Conductance Algorithm for Photovoltaic System Under Partial Shading Conditions and Load Variation IEEE Transactions on Industrial Electronics, 61, (10), 5384-5392. 